\title{
Wisdom in Pastoral Care and Counseling: What Does it Entail?
}

\author{
Bonnie J. Miller-McLemore
}

Published online: 26 July 2006

C Springer Science+Business Media, Inc. 2006

\begin{abstract}
The purpose of this article is to suggest richer potential meanings of spiritual wisdom and theological reflection in response to a critical reading of Pamela Cooper-White's book, Shared wisdom: Use of the self in pastoral care and counseling.
\end{abstract}

Keywords Countertransference $\cdot$ Wisdom $\cdot$ Self-awareness $\cdot$ Theological reflection

When I went up for membership in the Amcrican Association of Pastoral Counselors over sixteen years ago, I had just given birth. I was pregnant while seeing the client whosc case I presented-a young, European-American woman with questions about her recent marriage, sexual orientation, and spiritual experiences with Wicca. Three persons ran my accreditation interview-two European-American men and one Roman Catholic sister. Not one of them asked about the impact of my pregnancy on the therapy. This was not just a major oversight. Pamela Cooper-White's book, Shared wisdom: Use of self in pastoral care and counseling, suggests that this represents a limited and outdated understanding of selfhood, knowledge, and therapy.

That my interview committee did not ask how I had analyzed the role of my pregnancy should come as no surprise. Not to perpetuate stereotypes but of course a committee of two white men and a Catholic sister sixteen years ago did not consider the genderized context of care or see the pregnant body as sexual. Of greater interest in light of Cooper-White's book is their neglect of the powerful transferential and countertransferential feelings that my pregnancy must have evoked.

One of the more remarkable findings of a clinical social work dissertation that CooperWhite completed in 2000 is the large percentage of counselors who focus only on the conscious here-and-now. This finding laid the ground for Shared wisdom. Even though these counselors self-identify as psychodynamic in orientation, psychoanalytic ideas-that is, the

B. J. Miller-McLemore (M)

Pasıoral Theology and Counseling, Divinity School, Vanderbilt University, Nashville,

Tennessec 37240 , USA

e-mail: bonnie.miller-melemore@vanderbilt.edu 
examination of inner feelings and unconscious dynamics-are simply not "at the forefront" of their thinking (p. 167).

This finding, I suspect, set Cooper-White on a mission at least indirectly related to her earlier work, The cry of Tamar, that exposed many of the distorted assumptions commonly used to rationalize and justify violence toward women (Cooper-White, 1995). Shared wisdom aims to correct a narrow understanding of care that also misunderstands the nature of human desire in another way-by underestimating the power of unconscious, unmonitored desire. In simple terms, Shared wisdom is about countertransference and its beneficial use within therapy.

Countertransference is not a "problem" to be controlled. Nor is it simply projection of early childhood baggage onto the client (i.e., the "classical" view). It is a useful tool for understanding the self, the other, and the wisdom that arises between them. It includes the whole range of one's emotional and physical reactions or the "sum total of thoughts, feelings, fantasies, impulses, and bodily sensations, conscious and unconscious, that may arise in the pastoral caregiver in relation to any person who has come for help" (i.e., the "totalist" view) (p. 5). Cooper-White's thesis, briefly stated, is the more self-aware the helper the better the care (p. 8). Repeated mandates throughout the book for consistent, rigorous scrutiny of the multi-layered communications between helper and helpee through self-examination and consultation pertains to all levels of care, whether parish-based ministry, chaplaincy, or pastoral psychotherapy. For the latter, analysis of countertransference may even be, she argues, the "most important channel of information" about what is going on (p. 137).

All this seems simple but it is not. It is not easy for students in an introductory course on pastoral care to notice and use intense emotional reactions to figure out their unresolved personal issues or the important intersubjective information to which these feelings point. Nor have I found myself practicing the intrapsychic dissection Cooper-White encourages of my own thoughts, feelings, and bodily reactions now that I no longer practice depth-oriented psychotherapy on a regular basis. I would wager that even good analysts tire of this or fall easily into reliance on tried and true pet theories and analytic habits. It is also difficult to contain grandiose self-perceptions, a typical countertransference for all helpers in response to the neediness of those we help - that we are so wonderful, so wise, so special, and hence such good and needed helpers.

So Cooper-White's work is essential. She starts with history, turns to practice, and ends with theology. The first three chapters offer a primer, almost encyclopedia-style, of the history of countertransference in psychoanalytic, psychological, and pastoral counseling circles over the last century. Since my own training united Freudian with self-psychological theory and simply presumed the use of countertransference as a way to understand clinical dynamics, I was surprised how little Freud himself actually said about it and how cautious he was. One of his only two published papers on the topic employs military language of combat, control, and prevention. His wariness is laced with his own unanalyzed projections of woman as temptress. "The way these women manage to charm us," he bemoans, "with every conceivable perfection until they have attained their purpose is one of nature's greatest spectacles" (p. 10). Male analysts must steel themselves, he thinks, against their countertransferential desires.

This vigilance spread to the pastoral counseling movement. Anyone who went through Clinical Pastoral Education discovered that the major agenda was keeping one's own issues from getting in the way. Later pastoral literature is so captivated by a humanistic Rogerian focus on the present and real relationship that it makes almost no mention of countertransference at all.

Fortunately, alternative streams within this history, from Ferenczi to Winnicott to Kohutian-shaped pastoral therapy, suggest an improved non-pathological role for 
countertransference. Postmodernity itself has fostered new understandings of self and knowing that pave the way for the idea that wisdom lies in the intersubjective or transferential realm between client and therapist and not in some objective truth hidden in the psyche of the client waiting to be discovered by the expert theorist.

The remaining chapters turn to practice to explore and illustrate the usefulness of exploring transferential and countertransferential dynamics, moving from pastoral ministry to chaplaincy to pastoral psychotherapy to God imagery. A highlight of the book is the case analysis itself, where Cooper-White demonstrates the careful self-scrutiny for which she calls. Most cases in most books, I often warn students, are oversimplified. They condense meandering sessions, simplify complex details, and present the therapist as deft and insightful. Cooper-White sidesteps this by starting with four case studies where counseling went wrong. The pastor or pastoral therapist overreacts, oversteps, projects, misinterprets, and risks harming the one in need, sometimes dangerously so. Later Cooper-White returns to these scenes of potential disaster and plays with alternative scenarios in which the pastoral clinicians are more attuned to transference and employ strategies to sustain such attention. Equally gratifying, she heeds a major shift in pastoral theology and in counseling in general from a focus on the individual to the impact of the broader context. Each case looks at the crucial role of social and political difference, such as race, gender, and class.

As in the book itself, in the case analysis we come to the question of the place of theology in "shared wisdom" late. When psychological analysis is so helpful and so perceptive, as is often true, it is hard not to tack theology on at the end despite Cooper-White's best intentions and acknowledgement of this very problem (p. 152). Theology appears at the end of each case analysis. It is the final step in her suggested intervention method (p. 81) and it is the central subject matter of the concluding chapter of the book itself. Does this pattern, I wonder, suggest a limited understanding of theological wisdom? I think so. Is there more theology going on than meets the eye? Yes, if theology is understood less as theoretical proposition and more as a way of life. Does Cooper-White need to follow her own psychological advice but in the realm of theology instead of psychology and leave fewer theological rocks unturned for potential exploration? This, I believe, is also an interesting possibility and would deeply enrich this work.

Why, I wonder, did Cooper-White chose the word "wisdom," a deeply philosophical and theological word, for her main title and use it as a key metaphor within the text for the dynamics of transference? As she defines it, shared wisdom is the wisdom located between helper and helpee or, as Cooper-White says, the "pool of shared ... knowledge" that lies "in the 'between' of the intersubjective relationship-the potential space in which new insights can emerge through the shared exploration of meaning" (p. 128). But another kind of wisdom runs beyond this narrow mostly psychological definition. The book is also filled with rich nuggets of proverbial religious "truth." In particular, the book offers pragmatic guidance to Christian compassion for the other and, through such love, pragmatic guidance to the building of God's realm on earth. This desire to work toward the breaking-in of God's realm, I believe, is governed by her unspoken Protestant worldview and her theological proclivity and, ultimately, her countertransference on to us her readers (or perhaps the countertransference of her publishers on to their hoped for readers).

Cooper-White's pragmatic guidance inadvertently echoes the Book of Proverbs, an exemplary text of wisdom literature that draws fiom a long history of trial-and-error pithy sayings of simple truth for living the life of faith. One biblical dictionary describes proverbial wisdom as "a profound truth tested by the generations" or a "philosophy rooted in the soil of life," written to help the youth of its day "avoid all snares and dangers" (Blank, I962, p. 857). Shared wisdom contains a similar distillation of therapeutic relational, spiritual, and 
theologically knowing. The full affect of this wisdom rhetoric can come only from a more extensive reading of the text. But let me offer several examples:

- "Thirst for praise functions something like an addiction" (p. 107).

- "Emotional exploitation of others is the hallmark of narcissistic pathology" (p. 106).

- The most negative trait seen in others is the negative aspect "one wishes to disavow in oneself" (p. 115).

- Eros between helper and helpee may "signal not only sexual desire per se, but a deeper desire for life itself in all its excitement and fullness" (p. 117).

- An empowering approach requires humility and a recognition of "one's own limits objectively, without embarrassment or shame" (p. 129).

- "Planned incursions into a patient's private space almost always do more harm than good" (p. 151).

Each such claim embodies a rich, albeit hidden, theology that begs for recognition and articulation. Shared wisdom then, as I would redefine it and encourage Cooper-White to reconsider it, is theological know-how of the best kind embedded in the practices, rituals, and routines of the deeply knowledgeable helper.

Part of the problem is a truncated understanding of theological wisdom prevalent in the academy and doctrinal theology. Many twentieth-century systematic theologians conceptualized theology as propositional and removed from practice, a view Cooper-White sometimes adopts even though it has come under increased criticism in the past decade. The characterization of first, second, and third order theology upon which she relies has been questioned as an artificial separation of theory from practice that ignores the ways in which Christian theology is itself a practice (Tanner, 1997, pp. 72-73). Theologians, such as Kathryn Tanner, Serene Jones, and Mary McClintock Fulkerson, now situate systematic theology on a continuum with everyday theology of ordinary life. Both arise in a more "'organic' way out of Christian practice" (Tanner, p. 71).

Cooper-White says that theological reflection must await thorough analysis of countertransference. "Note that the process of theological reflection recommended here," she argues, "is not undertaken until after a thorough reflection on the countertransference and the implications for a pastoral assessment" (p. 74). Even though she says this is grounded in a postpositivist understanding of truth as embedded in context and on the idea of the living human document as pastoral text, isn't leaving theology until the end a modernist understanding that presumes theology has not already shaped the countertransference from the beginning? Isn't countertransference already deeply embedded in spiritual assumptions and theological projections? Isn't Cooper-White practicing theology from the start? Her theological method moves from free association of biblical and theological images, themes, and stories to more abstract claims. But I want to know how fundamental beliefs and practices arise in each case study from the beginning, how they come into crisis, and how they get revised in the thick of it all.

Cooper-White questions other modern dualisms of mind over body, reason over emotions, and so forth, except the one that has most interested me lately in my own work in spirituality and childhood studies: internal life over external life; cognition over practice; inner depth over outer existence; and the "God within" (Cooper-White, p. 189) over the God without (Miller-McLemore, 2006). Are reality and faith so located in our psyches, our interior, our quiet prayer time, and not in our everyday habits and activities? The view of spirituality as an interior matter misunderstands faith, at least in the Protestant tradition. Depth psychology's love for intrapsychic analysis has partly deepened and perpetuated this misunderstanding. The move to the intersubjective has not dispelled it because the 
intersubjective is still explored through an analysis of thought rather than an analysis of embodied practice.

No wonder two men and a Catholic woman did not see a pregnant body or care of children itself as spiritually relevant or psychologically meaningful. But for many religious traditions and not just Protestantism, wisdom is not just an internal, intellectual, intrapsychic mindgame; theological and spiritual wisdom requires practice, action, and concrete embodiment. Or perhaps this is my own transferential desire as I read Cooper-White's book and cast about for my own place as a Protestant feminist theologian in a world that no longer speaks theology.

One final implication of resituating wisdom and theology: more than Cooper-White wants to acknowledge, the helper functions as expert or wise person. She quotes pastoral theologian Judith Orr who argues that the idea that client and therapist stand in mutual relationship "begs for clarification." Yet Cooper-White shies away from Orr's and my own contention that many relationships, including therapy, represent temporary hierarchy and not just an "asymmetry" of "role and responsibility" (Cooper-White, pp. 56, 58-59; Orr, 2000; Miller-McLemore, 2004). Doesn't the helper know more, at some level, than the helpee? Doesn't she have psychological and theological wisdom of a distinctive kind? In fact, I am not sure how useful Shared wisdom is for "practitioners at all levels" (p. viii), despite CooperWhite's hope, because it actually requires an emotional and intellectual sophistication that many people cannot attain (pp. 53-54), as Robert Kegan suggests in his book, In over our heads. Before a clinician in one of the cases in Cooper-White's book can be of help, he needs, she says, individual therapy, spiritual direction, marriage counseling, professional consultation, wider reading, and regular prayer practice, and maybe even, one must wonder, a personality make-over. Moreover, just as Cooper-White wants the pastoral counselor to draw more facilely upon psychoanalytic theories of countertransference, I would also hope that the pastoral counselor might do more than theological free association and draw upon specific theological texts, scholars, and theories of human desire studied in graduate schools of religion.

In the end, Shared Wisdom contains more therapeutic wisdom in a fuller sense, as I have redefined it, than my response to the book can easily convey. The conceptual diagrams (e.g., pp. 45, 55-56) and footnotes alone are a rich resource. More importantly, I am thrilled to read a book so clearly biased toward a psychoanalytic view that the wider world still holds in suspicion. Cooper-White reminds us that "every act has meaning" (p. 178), calls us to notice emotionality in "its excess," and demonstrates that empathy is not about being nice but about conveying a deeper kind of comprehension. Not bad for starters as far as I am concerned. I am also grateful the book opens up so many other lively issues about the wisdom of the helper and the place of theology and faith that await our further engagement.

\section{References}

Blank, S. H. (1962). Wisdom. In The interpreter's dictionary of the Bible: An illustrated encyclopedia (pp. 852-861). Nashville: Abingdon.

Cooper-While, P. (1995). The cry of Tamar: Violence against women and the church's response. Minneapolis: Fortress.

Cooper-While, P. (2004). Shared wisdom: Use of the self in pastoral care and counseling. Minneapolis: Fortress.

Jones, S. (2002). Graced practices: Excellence and freedom in the Christian life. In M. Volf \& D. Bass (Eds.), Practicing theology: Beliefs and practices (pp. 51-77). Grand Rapids: Eerdmans.

Kegan, R. (1995). Over our heads: The mental demands of modern life. Cambridge: Harvard University Press. 
Miller-McLemore, B. (2004). Sloppy mutuality: Love and justice for children and adults. In E. Foley, B. Miller-McLemore, R. Schreiter, \& H. Anderson (Eds.), Mutuality matters: Faith, family, and just love (pp. 121-135). New York: Sheed \& Ward.

Miller-McLemore, B. (2006). In the midst of chaos: Caring for children as spiritual practice. San Francisco: Jossey-Bass.

Orr, J. (2000), Review of The mutuality of care by Roy Herndon SteinhoffSmith. Journal of Pastoral Theology, $10,218-219$.

Tanner, K. (1997). Theories of culture: A new agenda for theology. Minneapolis: Fortress. 